\title{
Influence of oxidation of automatic transmission fluids (ATFs) and sliding distance on friction coefficients of a wet clutch in the running-in stage
}

\author{
Leonardo Israel FARFAN-CABRERA ${ }^{1, *}$, Ezequiel Alberto GALLARDO-HERNÁNDEZ ${ }^{2}$, Manuel VITE-TORRES ${ }^{2}$, \\ Jesús Gilberto GODÍNEZ-SALCEDO ${ }^{3}$ \\ ${ }^{1}$ Tecnologico de Monterrey, Escuela de Ingeniería y Ciencias, Ave. Eugenio Garza Sada 2501, Monterrey 64849, México \\ ${ }^{2}$ Instituto Politécnico Nacional, SEPI-Escuela Superior de Ingeniería Mecánica y Eléctrica, Unidad Zacatenco, Grupo de \\ Tribología, Col. Lindavista, Ciudad de México 07738, México \\ ${ }^{3}$ Instituto Politécnico Nacional, ESIQIE, IPN, Col. Lindavista, Ciudad de México 07738, México \\ Received: 15 January 2019 / Revised: 06 July 2019 / Accepted: 18 May 2020 \\ (C) The author(s) 2020 .
}

\begin{abstract}
In this paper, the influence of oxidation of automatic transmission fluids (ATFs) and sliding distance on the friction coefficients of a wet clutch in approached running-in conditions was investigated. The ATFs were oxidized by a laboratory process approaching oxidation occurred in actual ATFs. Oxidation was evaluated by means of increase in carbonyl compounds and depletion of zinc dialkyldithiophosphates (ZDDPs) additives. Also, the changes in kinematic viscosity and viscosity index were evaluated. Pin-ondisk tests were conducted to replicate the actual sliding contact in a wet clutch. The pin specimens were cut from friction material composite plates and the disks were actual steel separators both from an automotive wet clutch. Friction coefficient, $\mu$, was measured at progressive sliding velocity, $v$, to obtain $\mu-v$ curves at 26 and $100{ }^{\circ} \mathrm{C}$. Three $\mu-v$ tests were consecutively run using the same pair of specimens and oil. The cumulative sliding distance for each $\mu-v$ test generated surface flattening using the oils. The friction coefficients of the wet clutch increased due to the ATFs oxidation meanwhile the $\mathrm{d} \mu / \mathrm{d} v$ values decreased in most cases. It suggests that ATF oxidation can enhance torque capacity of the wet clutch, but it could reduce anti-shudder property. Progressive sliding distance improved the slopes in the $\mu-v$ results using fresh ATFs meanwhile it generated a slope decrease by using aged ATFs.
\end{abstract}

Keywords: wet clutch; friction; oil oxidation; automatic transmission fluid (ATF)

\section{Introduction}

Wet clutches are components widely used for power shifting, lock-up, and continuously slipping to transmit torque in automatic transmissions (ATs) from cars. In a clutch engagement, as load is applied to press the set of plates with relative rotating motion, the automatic transmission fluid (ATF) film at the plates is squeezed, so sliding contact of the opposing surfaces occurs to transmit torque.
Torque transmission across the disk interface is due to viscous shearing of the ATF and asperities contact between the surfaces of the plates. Low tribological performance either from the ATF or plates produces poor torque transmission, which leads to increased fuel consumption, vehicle vibration, excessive wear of plates, and audible noise (squeal, chatter, and shudder) [1]. Therefore, an ATF must meet different requirements as hydraulic fluid and lubricant for the good performance of an AT.

* Corresponding author: Leonardo Israel FARFAN-CABRERA, E-mail: farfanl@hotmail.com 
For example, it must meet with low viscosity, high viscosity index, good lubricity, anti-wear, antioxidation, and anti-shudder properties, etc. [2]. In order to meet these requirements, an ATF is formulated with a mineral or synthetic base oils and different additives such as anti-wear agents, antioxidants, detergents-dispersants, and organic friction modifiers. The additives can interact individually or synergistically to contribute to its good performance, in particular, to the frictional characteristics of the wet clutch. Particularly, a wet clutch system is required to operate with high friction to reduce clutch engagement times and allow torque transmission, so both together ATF and clutch plates should generate these lubrication characteristics.

The progressive sliding of wet clutch plates produces alteration to the surface of the plates, which is majorly caused to the friction composite material plate's surface. It initiates with the running-in stage, in which both steel separator and friction disk surfaces are flattened by plastic deformation of metallic asperities and collapse of friction material composite pores reducing surface porosity. Afterwards, a darkened and either a smooth or shiny surface in the friction material disk is produced, which is ascribed to the formation of a thin smooth and shiny coating made of degraded products from the ATF on the pore structure by lodging effect. This is commonly known as "glazing" [3]. As glaze layer magnitude increases, surface porosity also decreases. The decrease in surface porosity limits ATF diffusion and permeability in the friction material as required in the ideal engagement condition to allow ATF squeezing through the engagements. Advanced glazing is very well identified by a thick shiny layer on the friction material surface, which rises temperature and wear, and reduces torque transmission capacity due to lower friction between the plates [3]. The continuous sliding, ATF degradation, surface flattening, and glazing of the friction plates may generate reduction of torque transmission capacity, but also undesirable self-excited vibrations by stick-slip effects, which is named as "shudder" [4]. It has demonstrated that shudder may occur when friction coefficient, $\mu$, in the clutch plates decreases as the sliding speed, $v$, increases, so a positive slope, $\mathrm{d} \mu / \mathrm{d} v$, therefore needs to be maintained in curves of friction coefficient versus sliding velocity $(\mu-v)$ to prevent shudder, in particular, in full scale tests since it depends on many factors included in the torque convertor operation [4-6].

Overall, since torque transmission performance of the wet clutch system completely depends on frictional performance, it is also indispensable that the friction properties can be maintained in both running-in and long-term use of wet clutch, especially in continuously slipping clutches [5]. It is well known that anti-shudder performance of an ATF in a wet clutch system is progressively affected by the high energy engagements and oxidation due to the AT's operation [7]. Watts et al. [8] evaluated the status of anti-shudder property of field ATF samples from actual lock-up clutches exhibiting shudder in an adapted SAE (Society of Automotive Engineers) \#II Friction Test Machine to determine the cause of the onset of vehicle shudder. In addition, lowvelocity friction apparatus (LVFA) tests were carried out to complement the analyses. They were useful to separate, in some extent, the contribution of hardware of SAE \#II machine to the loss of shudder control. It was found that shudder was produced due to rising static friction in the SAE \#II tester. Similarly, Li et al. [9] and Devlin et al. [6] studied the effects of glazing of clutch plates and the ATF ageing on the anti-shudder performance and torque capacity in wet clutches using the SAE \#II and LVFA tests, respectively. In most the studied cases, it was found that fluid ageing has larger influence on the anti-shudder durability than surface glazing. Although the SAE \#II and LVFA tests have been demonstrated as very suitable for the measurement of friction characteristics of wet clutches, it has been reported that the anti-shudder durability tests give no-correlated results between each other [7], which could be attributable to the influence of particular conditions that cannot be accurately controlled in each tester. In order to evaluate the friction characteristics of wet clutch under more controlled conditions, Berglund et al. [10] used a pin-on-disk test to investigate the effects of ATF ageing and different additive concentration on the friction characteristics 
of a wet clutch with plates made of sintered bronze friction material. The ATF was oxidized in lab by heating it up at $120{ }^{\circ} \mathrm{C}$ for five periods from 48 to $408 \mathrm{~h}$ by an oxidation stability test approaching the ageing process of a wet clutch used in a field test. Since the effect of surface alteration of plates on the friction was not their research purpose, the friction coefficients of new friction material composite samples under increasing sliding speeds at 30, 70 , and $100{ }^{\circ} \mathrm{C}$ were only assessed. In general, they found that friction increased with the ATF oxidation. In comparison to SAE \#II, LVFA, and other complex tests, pin-on-disk tests were found to be very inexpensive and time saving for large series of wet clutch testing allowing evaluations of many different combinations, including materials, ATFs, and test conditions. Moreover, it allowed an easy and accurate control of test parameters and measurement of more local friction [11]. It was also found to be a suitable and alternative option to obtain measurements of friction coefficient versus sliding speed using ATFs and friction material composites for wet clutch $[10,12]$. The results of friction coefficients at different temperatures, contact pressures, and sliding speeds from this method have been found to correlate well with results obtained from a SAE \#II machine [11, 13].

Although there are some reported attempts to recognize the effects of ATF oxidation and surface damage of plates on the frictional behavior of wet clutches, it is not well understood yet, especially in the running-in stage. Measurements of local friction of wet clutch plates under controlled sliding distance, temperature, speed, load, and ATF condition discarding other effects can be helpful for achieving a better understanding.

Hence, this research paper aims to contribute with an evaluation of the influence of oxidation of two commercial ATFs and the progression of surface alteration of friction material composite plates caused by progressive sliding distances on the friction coefficients of a wet clutch. The tests were carried out in a pin-on-disk tester at increasing speeds approaching the wet clutch sliding interface in the running-in stage.

\section{Material and methods}

\subsection{Oil samples}

The lubricants tested were two common ATFs with different specifications, which will be named in the following as: 1ATF and 2ATF. 1ATF meets the specification for DEXRON ${ }^{\circledR}$ III, Ford MERCON ${ }^{\circledR}$, and Allison C-4/C-3 meanwhile 2ATF meets only the specification for MERCON ${ }^{\circledR} \mathrm{V}$ according to the oil data sheets, respectively. They were selected to evaluate two oils meeting different ATF specifications. The oils were exposed to a laboratory thermal ageing process [14] which was developed based on Ref. [15] in order to approach oxidation occurred in actual ATFs in automotive transmissions with the long-term use. The oil oxidation produced in laboratory has been demonstrated as a useful tool to study specific degradation characteristics of oils under controlled conditions [16]. The oil ageing set-up can be seen in Fig. 1. This method has been demonstrated as a pronounced short-term method to investigate the long-term behavior of automotive oils enabling the pre-selection thereof according to their performance under controlled conditions. It consisted on oxidizing an oil sample of $300 \mathrm{~g}$ in a sealed glass vessel at $160{ }^{\circ} \mathrm{C}$ for $60 \mathrm{~h}$ by using a stirring hot plate with temperature control with $\pm 0.5{ }^{\circ} \mathrm{C}$ of accuracy. The temperature selected for the oil ageing corresponds to an average of the highest temperatures occurred at the interface of wet clutch plates during engagement $[17,18]$. Two conduits made of glass for air inlet and exhaust gases were adapted to the vessel. The air was introduced in the oil through the air inlet conduit in order to facilitate the oxidation process and agitate the sample during the test. The air flow was adjusted at $10 \mathrm{~L} / \mathrm{h}$ as suggested in the method. The relative air humidity was measured to be in the range of $40 \%-50 \%$. Also, a thermometer was immersed in the oil to measure temperature. Although this method has demonstrated an acceptable correlation with mineral oils used in actual operating conditions, there are not specific information about the correlation of oxidation of ATFs in lab with those oxidized in actual ATs. Thus, to have a reference of the oxidation caused in lab by this method, one of the oils (2ATF) 


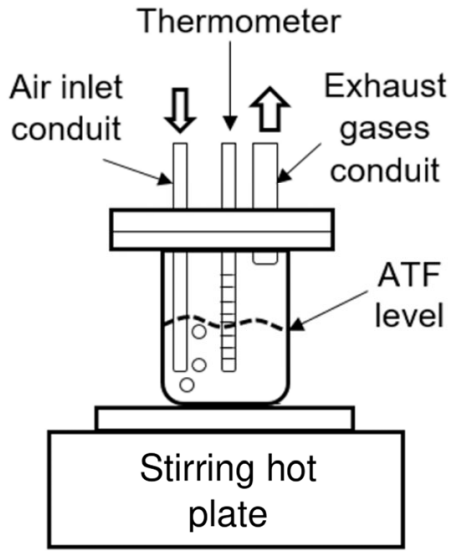

Fig. 1 Schematic view of the laboratory thermal ageing set-up.

was additionally aged in a field test to be compared with the 2ATF oxidized in lab. For this, the oil was used in a new car equipped with an AT with torque converter. After a use of 50,000 km, considered as a substantial use period for an ATF in a passenger car, the ATF was extracted to analyze the oxidation produced.

The standard method ASTM D-7214 was carried out to evaluate oxidation caused in the ATFs. It consisted on determining oxidation of oils by Fourier transform infrared (FTIR) analysis by measuring the change in concentration of constituents containing a carbonyl function that have formed during the oxidation process. FTIR spectra of the fresh and aged oil are recorded in a transmission cell of known pathlength. Both spectra are converted to absorbance and subtracted. Using the differential spectrum, a baseline is set under the peak corresponding to the carbonyl region between 1,650 and $1,820 \mathrm{~cm}^{-1}$. The area created by this baseline and the carbonyl peak is calculated and then divided by the cell pathlength. The result is reported as peak area increase (PAI). Also, the standard method ASTM D-7412 was used to monitor the depletion of zinc dialkyldithiophosphates (ZDDPs) additives, which are contained in the ATFs tested according to the datasheet. The specific concentration of ZDDPs was not provided by the manufacturer. However, the standard method based on FTIR analyses helped to visualize the change in absorbance corresponding to ZDDPs in function of thermal ageing. These additives are the most used in the formulation of mineral and synthetic ATFs to reduce friction and wear of metallic components, but mainly to prolong oil oxidation resistance. The content of additives of the oil samples was estimated from each FTIR spectrum by using the direct trend analysis measurement in the area between 960 and $1,025 \mathrm{~cm}^{-1}$ and the minimum and maximum baseline points, 700 and $1,900 \mathrm{~cm}^{-1}$, respectively. Both analyses were performed using a spectrometer micro Raman coupled to an ATR (objective $36 \times$ ) from a module FTIR (IR2). The cell pathlength was set at $0.05 \mathrm{~mm}$. The spectral data was collected between 700 and $1,900 \mathrm{~cm}^{-1}$ averaging 32 scans with a resolution of $4 \mathrm{~cm}^{-1}$. The data range was selected accordingly to meet the required spectra for analysis in both standard methods.

In addition, the viscosity changes occurred by thermal ageing were evaluated. Dynamic viscosities were measured by using a rotational rheometer with a cone/plate configuration at 26,40 , and $100{ }^{\circ} \mathrm{C}$. The kinematic viscosities were calculated by considering the dynamic viscosities and densities obtained. Also, the viscosity indexes were estimated by the ASTM D-2270 standard procedure in which the kinematic viscosities at 40 and $100^{\circ} \mathrm{C}$ were considered. All the tests mentioned above were carried out for the fresh and aged samples.

\subsection{Friction test}

The friction tests were carried out using a test configuration in a pin-on-disk tester under specific controlled conditions to approach the sliding contact of an actual wet clutch. The schematic view of the test set-up used can be seen in Fig. 2. Constant normal loads, oil temperatures, and rotational speeds could be evaluated in the tester. The pin and disk specimens and the corresponding holders are illustrated in Fig. 3. The pin and disk samples were prepared from the selected wet clutch plates. The friction disks corresponded to plates of resin- filled cellulose (friction material composite) bonded to a steel backing plate. This class of material is used in the market for common wet clutches from powershift transmissions in passenger cars [19]. The disk samples were new steel plates made of high carbon steel with material specification CS 70 according to the manufacturer data sheet. They have a thickness of $1.9 \mathrm{~mm}$, hardness of $255 \mathrm{HB}$, 
and surface roughness (Ra) of $0.22 \pm 0.03 \mu \mathrm{m}$. The actual housing of the wet clutch was modified and adapted to operate as the disk holder and oil container to secure the disk (steel plate) in the proper position for the test and to contain the oil to be tested. The holder for the pin specimen was manufactured in order to secure small rounded specimens of $9 \mathrm{~mm}$ in diameter. For the test, the pin specimen was positioned at the end of the pin holder in a small cavity. A small spherical setting arrangement in the lower part of the pin holder that moves about a central point was manufactured to allow alignment of the flat pin sample to the disk surface. The load was axially applied via dead weights to the friction material composite sample being in full contact with the steel disk surface. The pin on disk contact was entirely immersed in lubricant during the whole test using $100 \mathrm{~mL}$ of oil. The friction force generated by the sliding between the pin and disk specimens was measured and logged by using a load sensor and a data acquisition software. The friction coefficients were evaluated at different sliding speeds ( $\mu-v$ test). The test conditions can be seen in Table 1 . The tests started with a velocity of $0.05 \pm 0.01 \mathrm{~m} / \mathrm{s}$, which was increased in increments of $0.06 \pm 0.01 \mathrm{~m} / \mathrm{s}$ up to $0.9 \pm 0.01 \mathrm{~m} / \mathrm{s}$

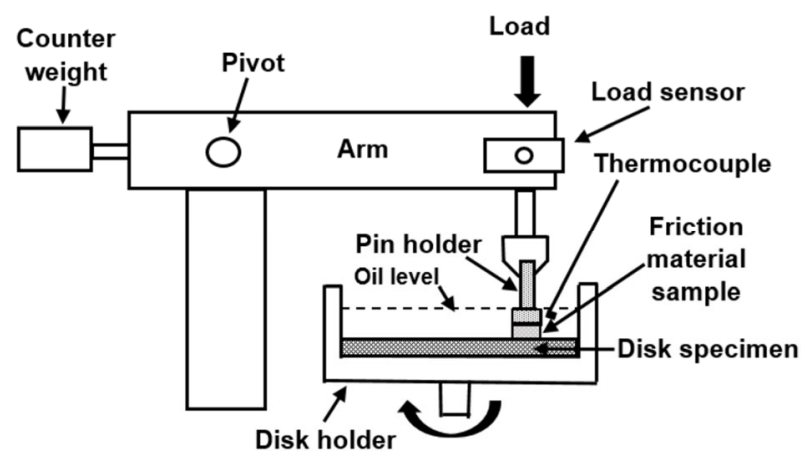

Fig. 2 Schematic view of the pin-on-disk set-up.

Table 1 Friction test parameters.

\begin{tabular}{llll}
\hline Test parameter & $1^{\text {st }}$ Run & $2^{\text {nd }}$ Run & $3^{\text {rd }}$ Run \\
\hline $\begin{array}{l}\text { Load }(\mathrm{N}) \\
\text { Contact }\end{array}$ & 51 & 51 & 51 \\
pressure $(\mathrm{MPa})$ & 0.8 & 0.8 & 0.8 \\
$\begin{array}{l}\text { Oil } \\
\text { temperature }\left({ }^{\circ} \mathrm{C}\right)\end{array}$ & $26 \pm 1,100 \pm 1$ & $26 \pm 1,100 \pm 1$ & $26 \pm 1,100 \pm 1$ \\
$\begin{array}{l}\text { Sliding } \\
\text { speed }(\mathrm{m} / \mathrm{s})\end{array}$ & $0.05-0.9$ & $0.05-0.9$ & $0.05-0.9$ \\
$\begin{array}{l}\text { Sliding } \\
\text { distance }(\mathrm{m})\end{array}$ & $0-634 \pm 1$ & $634 \pm 1-1269 \pm 1$ & $1269 \pm 1-1904 \pm 1$ \\
\hline
\end{tabular}

using the same sample pairs. Although anti-shudder standard tests are usually carried out at speeds lower than $0.05 \mathrm{~m} / \mathrm{s}$, the dynamic friction coefficient could be measured till a minimum speed of $0.05 \mathrm{~m} / \mathrm{s}$ due to the capabilities of the pin-on-disk tester used.

The friction force was measured for each speed interval for a period of $90 \mathrm{~s}$, collecting $10 \mathrm{data} / \mathrm{s}$. It was selected since the standard deviation of friction coefficient for this period was found to be lower than $0.015 \pm 0.001$ in previous trials, which suggested friction coefficient stability by using this measurement period. In total, for each $\mu-v$ test, 15 different velocities were tested, completing a sliding distance of $634 \mathrm{~m}$. Since the surface of friction material composite plates is altered by the progressive sliding distance, the same pair of specimens and oil sample were used again to conduct other two tests consecutively under similar conditions to examine different levels of surface alteration. The surface alteration was assessed in terms of changes in surface roughness (Sa) by using an optical profilometer with an objective of $5 \times$.

The friction coefficient at different sliding speeds was evaluated for three consecutive sliding distances. The first run was in the range from 0 to $634 \mathrm{~m}$, the second run was from 634 to $1,269 \mathrm{~m}$, and the third run was from 1,269 to $1,904 \mathrm{~m}$. Since there are not published results about the surface alteration of friction disks under the certain friction test conditions used for this work, several pre-tests were carried out to achieve homogeneous and visible surface alteration (flattening and darkening) on the samples by generating stable friction coefficient through the whole tests. A normal load of $51 \mathrm{~N}$ was used to generate an apparent contact pressure of $0.8 \mathrm{MPa}$ to be in range of contact pressures (0-2.9 $\mathrm{MPa}$ ) generated in actual wet clutches from automatic power shift transmission of moving off-road vehicles $[13,20]$. Each oil sample at each temperature was tested by using a new pair of pin and disk specimens. Three friction tests under similar conditions for each oil and each temperature were performed. The tests were run at two oil temperatures (26 and $100 \pm 1{ }^{\circ} \mathrm{C}$ ) to replicate the operation temperature of an automatic transmission under starting-up and overheating conditions, respectively. Also, they were selected due to the minimum and maximum temperature control capabilities of the tester used. 

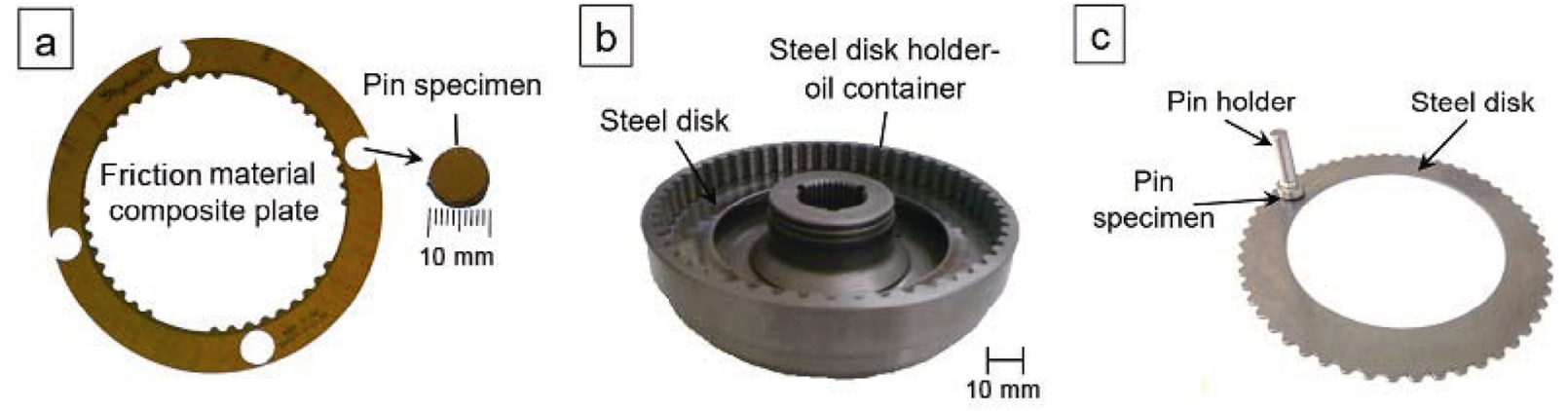

Fig. 3 (a) Pin specimen/friction material sample; (b) steel disk specimen and disk holder/oil container; and (c) representation of the pin-on-disk configuration used for the friction test.

\section{Results and discussion}

\subsection{Effects of thermal ageing on ATFs}

\subsubsection{Oxidation}

The FTIR spectra obtained from both fresh and aged oils are shown in Figs. 4(a) and 4(b), respectively. The spectrum ranges considered for the standard measurements (ASTM D-7214 and ASTM D-7412) are also indicated in these figures. In general, for mineral oils, the oxidation is mainly represented by increase in the area between 1,650 and $1,820 \mathrm{~cm}^{-1}$, which is known as the carbonyl region. The growth of such an area is mainly caused by the absorbance increase in the peak near to $1,728 \mathrm{~cm}^{-1}$. Another common effect of thermal ageing in ATFs is the depletion of additives, in particular, ZDDPs. The area created by the absorbance in the peak near to $968 \mathrm{~cm}^{-1}$ represents the content of this kind of additives in the sample according to that specified in the standard method ASTM D-7412, so a decrease of intensity of this area suggests ZDDPs depletion. In the spectra, absorbance in the peaks near to 1,377 and $1,460 \mathrm{~cm}^{-1}$ was also identified. The absorbance of these peaks suggests the content of mineral oil molecules with $\mathrm{C}-\mathrm{H}$ bonds modes [21], which are representative of the ATFs tested. In Fig. 4(b), the spectra from 2ATF used in the field test are additionally shown to be compared. The ageing produced in 2ATF by the laboratory and field ageing tests did not correlate closely since 2ATF aged in the field test exhibited higher additives depletion and higher increase in the carbonyl region than those presented in 2ATF aged in lab. On the other hand, comparing qualitatively both Figs. 4(a) and 4(b), 2ATF exhibited higher increase of absorbance in the carbonyl region than $1 \mathrm{ATF}$, which suggested that it was more oxidized. Also, higher absorbance of the peak near to $968 \mathrm{~cm}^{-1}$ in both spectra from 2ATF can be seen, which suggested that this oil had higher ZDDPs concentration than 1ATF. This can be more clearly seen in Figs. 5(a) and 5(b), in which a quantitative comparison of PAI value and ZDDPs concentration obtained from the oils is shown, respectively. Although 2ATF had higher ZDDPs concentration than $1 \mathrm{ATF}$, it was more affected by the thermal ageing. It was perhaps due to a better refining quality of its base oil or the content of other additives incorporated in the formulation of 1ATF. Thus, it can be said that $1 \mathrm{ATF}$ was more resistant to oxidation by thermal ageing than 2ATF. 2ATF used in the field test presented higher ZDDPs depletion and oxidation than 2ATF aged by the laboratory test, suggesting that the ageing characteristics evaluated did not correlate exactly under those conditions. So, more laboratory and field tests under different conditions, chemical evaluations and testing of other ATFs are needed to support and enhance the technical accuracy of this oxidation method.

It is noteworthy that the ATFs ageing could be also influenced by the humidity existing during the aeration for the ageing process. This can produce a rapid reverse of micelles formation and acceleration of oil degradation as reported in other research works $[22,23]$. Another consequence is the detriment of tribological performance of ZDDPs due to the depolymerization of longer chain phosphates by the oil contamination with water [24]. The oxidation of mineral oils is mainly evaluated by means of increase in carbonyl compounds and depletion of 

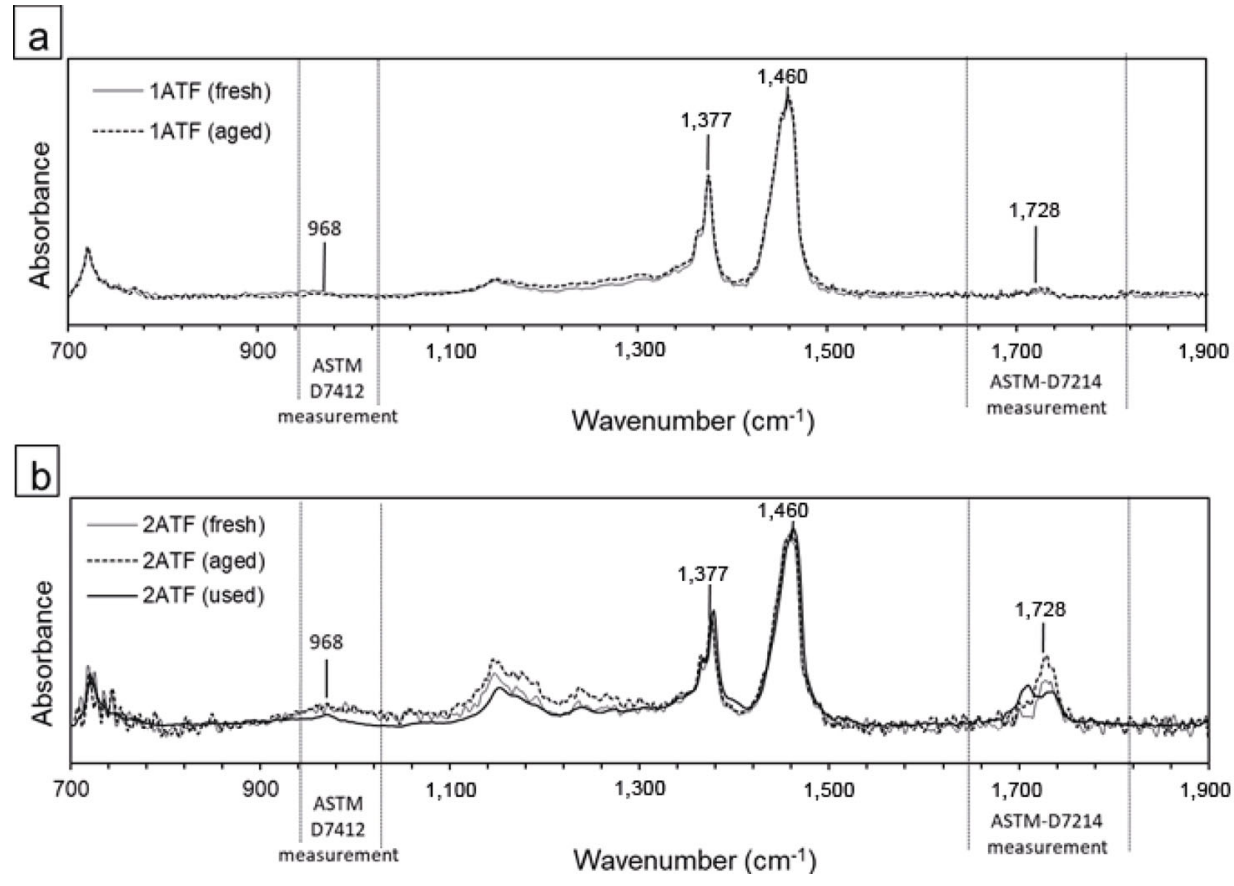

Fig. 4 FTIR spectra from the fresh and aged ATFs samples: (a) 1ATF; (b) 2ATF.
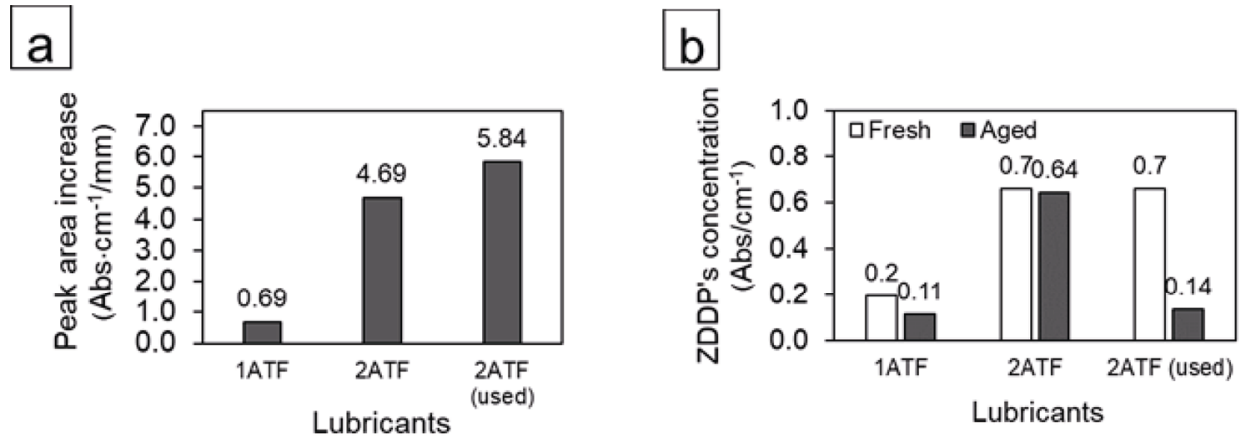

Fig. 5 (a) Comparison of oxidation (PAI values) caused in the ATFs; (b) comparison of ZDDP concentration.

anti-oxidant additives, such as ZDDPs. However, ageing involves other changes in the base oil and other chemical compounds (additives) contained in an ATF, namely, friction modifiers, dispersants, detergents, etc., which can also have an effect in the friction coefficients of the wet clutch [22]. The study of the effect of oxidation of each of the above additives either independently or synergistically on the wet clutch friction requires extensive further work.

\subsubsection{Changes in viscosity}

The comparison of viscosities for the fresh and aged ATFs at 26,40 , and $100{ }^{\circ} \mathrm{C}$ are shown in Figs. 6(a)-6(c), respectively. 1ATF exhibited a negligible increase of viscosity (less than $1 \mathrm{cSt}$ ) at all the temperatures tested after the ageing process while 2ATF presented a much higher viscosity increase. It can be attributed to the increase of the carbonyl region found in the spectra of this oil, as seen in Fig. 5(b), since the carbonyl compounds induce hydrogen bonding, dipole, and van der Waals interactions among the constituents present in mineral and synthetic oils and contribute to change viscosity [25]. In general, the increase of viscosity in ATFs can enormously compromise efficiency of an AT, mainly at low temperatures, since the ATF fluidity may be reduced producing deficiencies in the clutch engagement either by its performance as hydraulic fluid or as wet clutch lubricant. Moreover, 

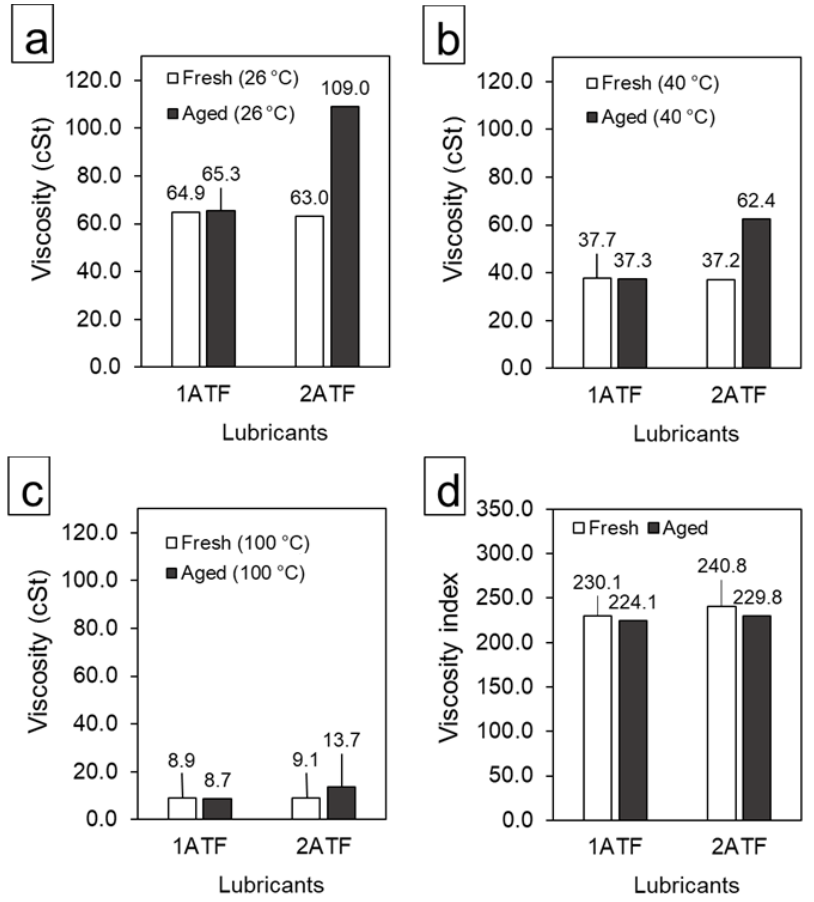

Fig. 6 Comparison of kinematic viscosity of fresh and aged ATFs at: (a) $26{ }^{\circ} \mathrm{C}$; (b) $40{ }^{\circ} \mathrm{C}$; and (c) $100{ }^{\circ} \mathrm{C}$; (d) comparison of viscosity index for the fresh and aged ATFs.

a high viscosity index is required for ATFs to limit considerably the change of oil viscosity by temperature effects. In Fig. 6(d), the comparison of viscosity index of the fresh and aged oils is shown. In general, the viscosity index from both ATFs decreased with thermal ageing. However, 2ATF exhibited the highest viscosity index before and after the ageing process.

\subsection{Friction coefficients}

The comparisons of the friction coefficients against sliding speed from three consecutive runs of fresh and aged ATFs at 26 and $100{ }^{\circ} \mathrm{C}$ can be seen in Figs. 7 and 8 , respectively. The friction coefficient results represent the average of the data measured for $90 \mathrm{~s}$ for each sliding speed from the three repetition tests. The standard deviation found for friction coefficient from the three repetitions at each speed was lower than 0.016 . In all the plots, the results of friction coefficient exhibited increase or decrease with sliding speed accordingly. They were fitted by a curve with linear trend to calculate the average slope of each curve corresponding to the $\mathrm{d} \mu / \mathrm{d} v$ value. The comparisons of $\mathrm{d} \mu / \mathrm{d} v$ values from the three consecutive runs for the fresh and aged ATFs at 26 and $100{ }^{\circ} \mathrm{C}$ are shown in Figs. 9 and 10, respectively. Also, the variation of the slope value obtained from the repetition tests is given.
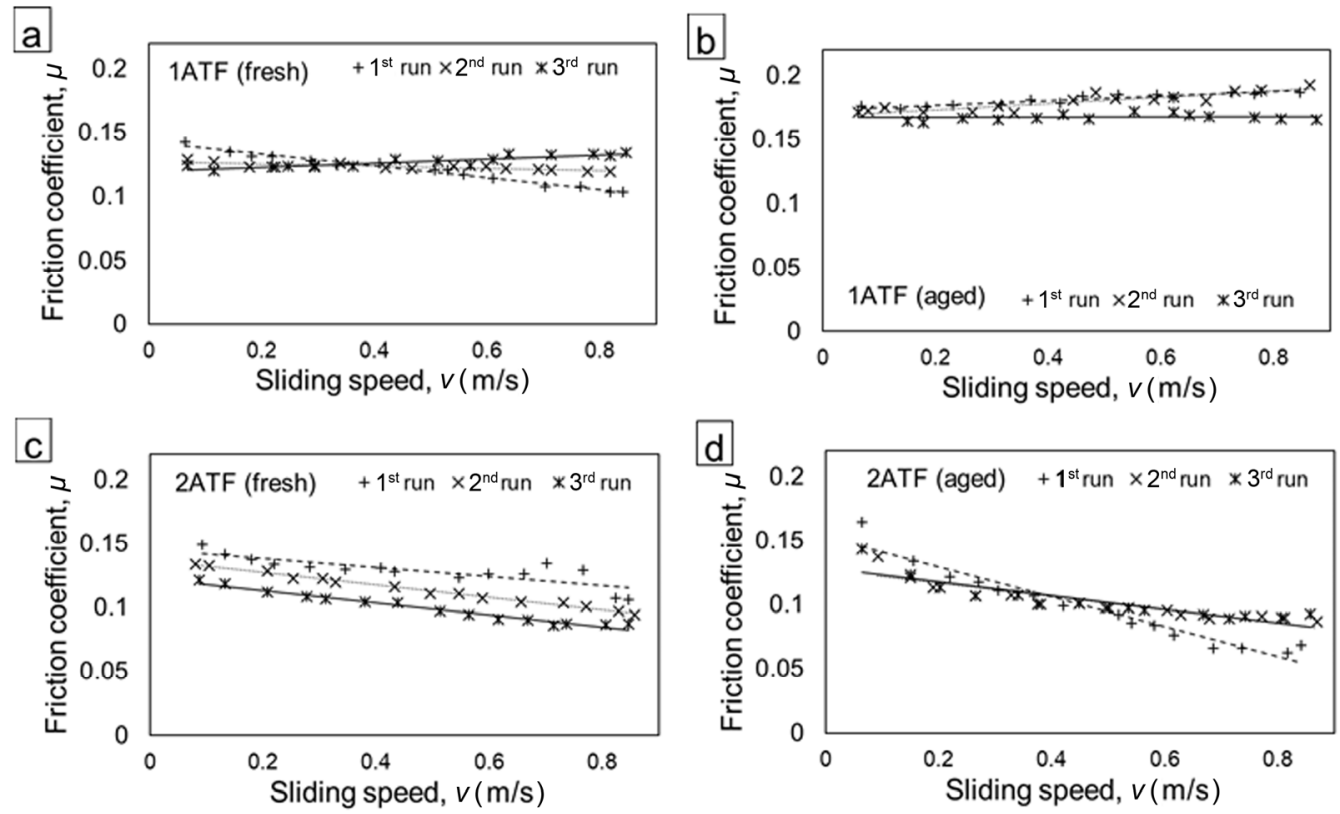

Fig. 7 Friction coefficient against sliding speed for three consecutive runs at $26{ }^{\circ} \mathrm{C}$ of the different fresh and aged ATFs: (a) 1 ATF (fresh); (b) 1ATF (aged); (c) 2ATF (fresh); and (d) 2ATF (aged). 

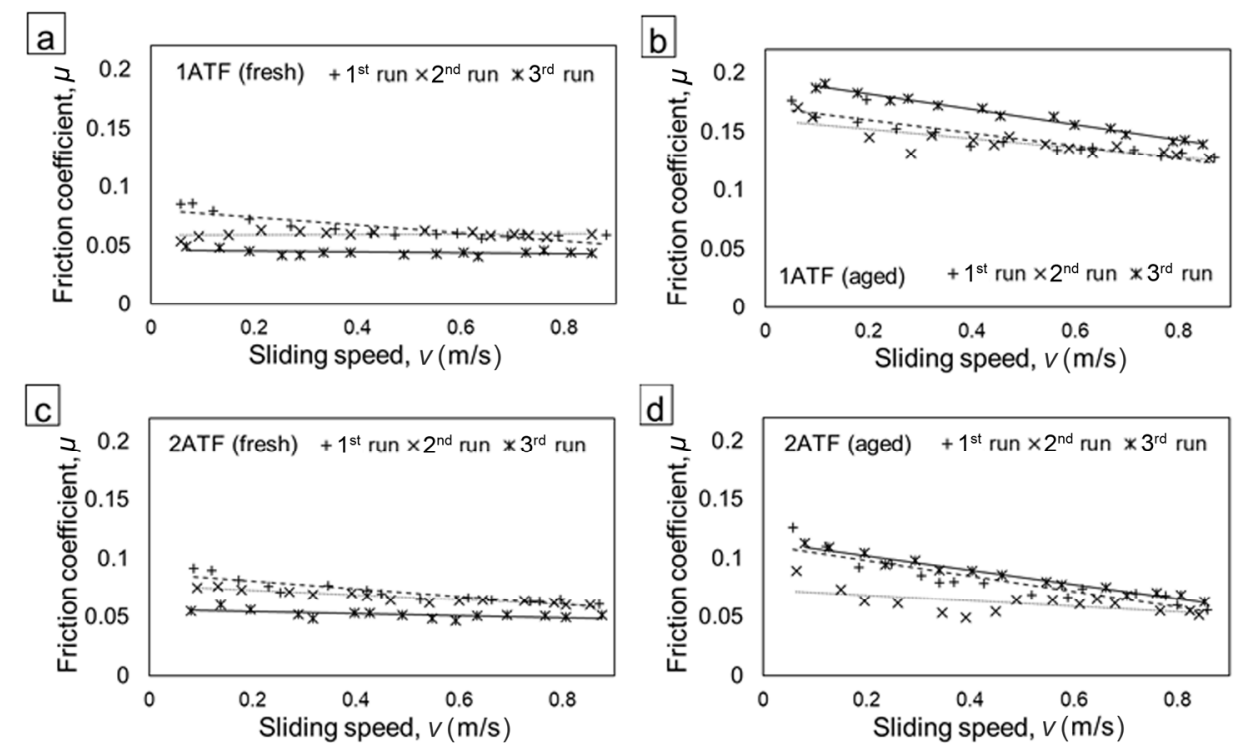

Fig. 8 Friction coefficient against sliding speed for three consecutive runs at $100{ }^{\circ} \mathrm{C}$ of the different fresh and aged ATFs: (a) $1 \mathrm{ATF}$ (fresh); (b) 1ATF (aged); (c) 2ATF (fresh); and (d) 2ATF (aged).
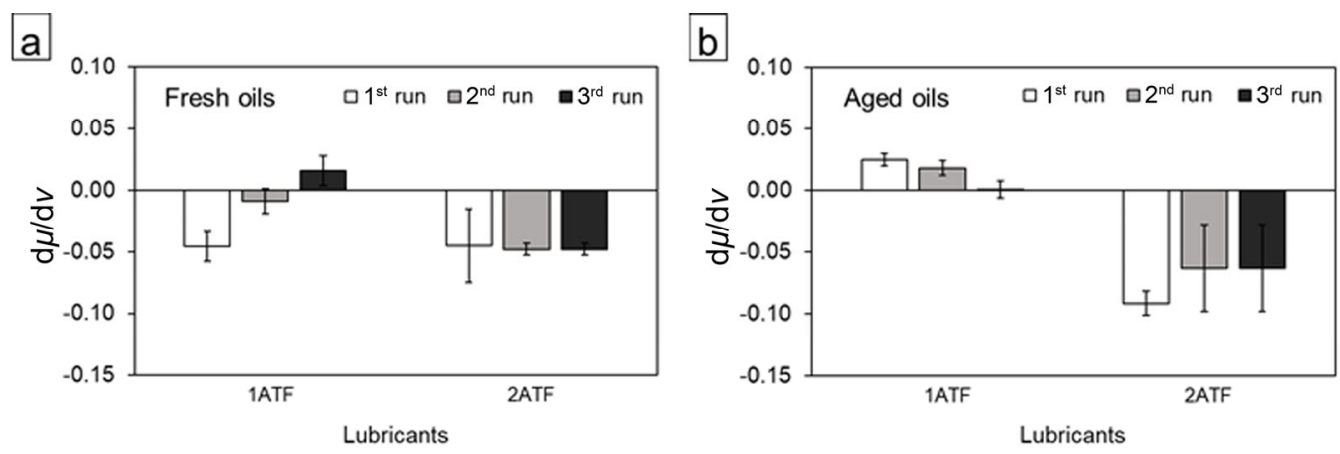

Fig. $9 \mathrm{~d} \mu / \mathrm{d} v$ values obtained at consecutive runs at $26^{\circ} \mathrm{C}$ for the ATFs: (a) fresh; (b) aged.
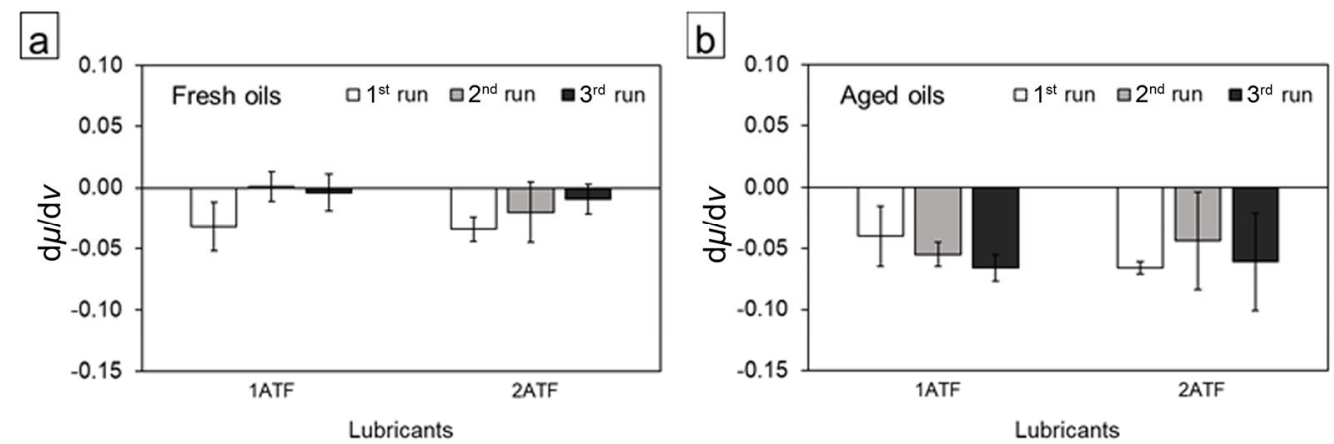

Fig. $10 \mathrm{~d} \mu / \mathrm{d} v$ values obtained at consecutive runs at $100{ }^{\circ} \mathrm{C}$ for the ATFs: (a) fresh; (b) aged.

\subsubsection{Influence of ATF oxidation on wet clutch friction}

According to Figs. 7 and 8 , aged 1ATF at both temperatures and $2 \mathrm{ATF}$ at $100{ }^{\circ} \mathrm{C}$ exhibited increase of friction coefficients mainly at low sliding speeds, which can be mainly attributed to additives depletion, such as ZDDPs and friction modifiers as that reported by Zhao et al. [26]. They reported that friction modifiers have a considerable effect of reducing friction coefficient at low speed as well as detergents help to enhance the anti-shudder property of ATFs.

The oxidation of ATFs increased friction as that reported by Berglund et al. [10] for a sintered bronze 
friction material. Comparing both ATFs, 1ATF exhibited the highest increase in friction coefficients at both temperatures by oxidation. 1ATF (fresh and aged) had less concentration of ZDDPs than 2ATF as seen in Fig. 5(b), so the friction increase exhibited by 2ATF (aged) could be ascribed to the low concentration and depletion of ZDDPs and friction modifiers. The increased friction in a wet clutch by the oil oxidation may be considered as positive since it increases the capacity of torque transmission of wet clutch $[1,10]$. However, it could be negative if friction is only raised at low sliding speeds because it can decrease the anti-shudder property. In Figs. 9 and 10 , the change in $\mathrm{d} \mu / \mathrm{d} v$ value by oxidation of the ATFs at 26 and $100{ }^{\circ} \mathrm{C}$ can be seen, respectively. Comparing the first run results to discard surface alteration in some extent, 2ATF exhibited a slope decrease at both temperatures after being oxidized meanwhile $1 \mathrm{ATF}$ only decreased at $100{ }^{\circ} \mathrm{C}$ due to oxidation. 1ATF exhibited higher $\mathrm{d} \mu / \mathrm{d} v$ values than 2ATF after being aged. Also, 1ATF presented an increase of friction coefficient with sliding speed at $26{ }^{\circ} \mathrm{C}$ due to oxidation. It may be due to $1 \mathrm{ATF}$ was less oxidized than 2ATF by the thermal ageing process (1ATF producing less carbonyl constituents than 2ATF), so oxidized products from ATFs, in particular, carbonyl compounds could reduce the anti-shudder behavior of ATFs.

\subsubsection{Influence of sliding distance on wet clutch friction}

In Figs. 7 and 8, the friction coefficients exhibited difference between each run, meaning that surface alteration produced by progressive sliding distance can increase or decrease friction. Typical optical images from the surface of the pin samples before and after being tested for the three runs by using both fresh and aged ATFs at $100{ }^{\circ} \mathrm{C}$, are illustrated in Figs. 11(a)-11(e), respectively. Figure 11(a) shows the friction material's surface before testing meanwhile Figs. 11(b, c) and 11(d, e) illustrate the typical surface alteration produced on the friction material samples for the total sliding distance $(1,904 \mathrm{~m})$ using $1 \mathrm{ATF}$ and $2 \mathrm{ATF}$, respectively. It was found that the surface damage generated on the samples was quite similar at both temperatures $\left(26\right.$ and $\left.100{ }^{\circ} \mathrm{C}\right)$. The decrease in porosity reduces the ATF porous diffusion in the friction material composite [3,7], promoting the formation of larger ATF film thickness during sliding [27]. According to Figs. 7(a, c) and 8(a, c), both fresh ATFs exhibited a decrease of friction coefficient at the different sliding speeds with
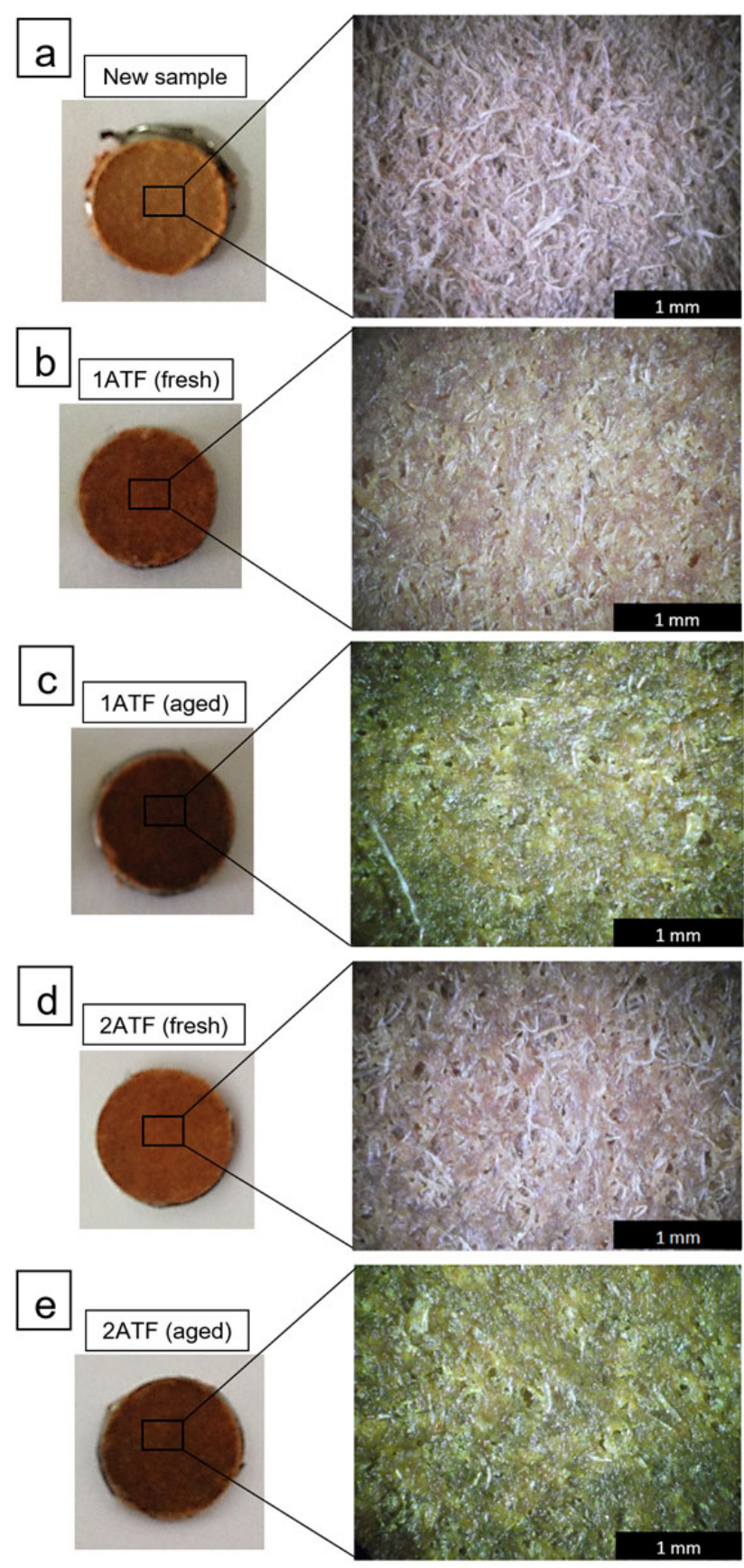

Fig. 11 Micrographs from typical surface of pin specimens before and after being tested using the different oils: (a) untried sample; (b) using fresh 1ATF; (c) using aged 1ATF; (d) using fresh 2ATF; and (e) using aged 2ATF. 
progressive sliding distance (2 ${ }^{\text {nd }}$ and $3^{\text {rd }}$ runs) in contrast to the results from the $1^{\text {st }}$ run (shortest sliding distance). So, progressive sliding distance reduces friction coefficient in wet clutch using fresh ATFs. It could be possible due to that sliding motion enhances the $\mathrm{C}-\mathrm{OH}$ groups' adsorption on the friction material wear track reducing friction coefficient as found and reported in Refs. [26, 27]. $\mathrm{C}-\mathrm{OH}$ groups came from the organic friction modifier's hydrophilic head group and could contribute to favorable surface triboreactions [26]. In contrast, according to Figs. 7(b, d) and 8(b,d), both aged ATFs exhibited increased friction coefficients at the different sliding speeds with progressive sliding distance $\left(2^{\text {nd }}\right.$ and $3^{\text {rd }}$ runs) contrary to the results from the $1^{\text {st }}$ run (shortest sliding distance). Considering the oxidation caused to the ATFs by thermal ageing, friction modifiers perhaps were also depleted. In a similar way, these effects of thermal ageing on the friction modifiers also promoted variations in the $\mathrm{d} \mu / \mathrm{d} v$ value. According to Figs. 9 and 10, fresh ATFs exhibited an increase of $\mathrm{d} \mu / \mathrm{d} v$ value for the three runs at both temperatures in contrast to aged ATFs, meaning that the surface alteration $(\mathrm{C}-\mathrm{OH}$ groups' adsorption on the friction material wear track) by the progressive sliding using fresh ATFs could be beneficial for the antishudder property in contrast to that alteration formed by the aged oils, in which friction modifiers are depleted.

The changes in surface roughness of the samples can be a representation of the surface porosity changes occurred. The comparison of the changes in surface roughness of the friction material samples generated by using both oils for the total sliding distance at

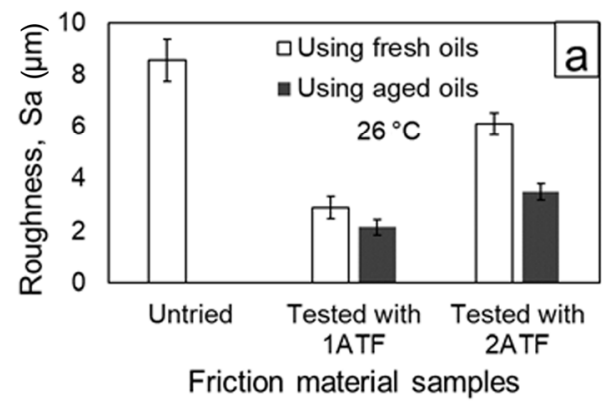

26 and $100{ }^{\circ} \mathrm{C}$ is shown in Figs. 12(a) and 12(b), respectively, meanwhile the comparison of surface roughness of the tested steel plates is depicted in Fig. 13. The friction material samples and steel plates exhibited a decrease of surface roughness for all the cases. It suggests that porosity of friction material samples decreased with sliding distance while surface of steel plates was polished. It may be other reason for the decrease in friction coefficients seen in Figs. $7(\mathrm{a}-\mathrm{d})$ and $8(\mathrm{a}, \mathrm{c})$. The sliding distance tested was not enough to produce a significant glaze layer on the friction material surfaces. So, longer distances are further required to evaluate more advanced stages of alteration of the wet clutch disks surfaces.

Holgerson [20] reported results of different parameters measured during the engagement in a wet clutch apparatus approaching actual conditions of an AT. The tests were carried out with input parameters that simulated an actual gear change in an AT at 4,000 rev/min and 50\% throttle. The starting sliding speed in the wet clutch was $20.9 \mathrm{~m} / \mathrm{s}$, the drive torque was $23.6 \mathrm{~N} \cdot \mathrm{m}$ with an inertia of $0.0081 \mathrm{~kg} \cdot \mathrm{m}^{2}$, the maximum pressure was $1.4 \mathrm{MPa}$ and mean pressure of $0.8 \mathrm{MPa}$ for an engagement time of 0.67 s. In Fig. 14, the mean linear trend curve of the speed change against engagement time obtained from those experiments is shown. The sliding distance, $s$, in the engagement can be calculated by:

$$
s=\int_{0}^{t} v \mathrm{~d} t
$$

where $v$ is velocity and $t$ is the engagement time. Hence, the change of velocity with time was calculated by:

$$
v=-31.194 t+20.9
$$

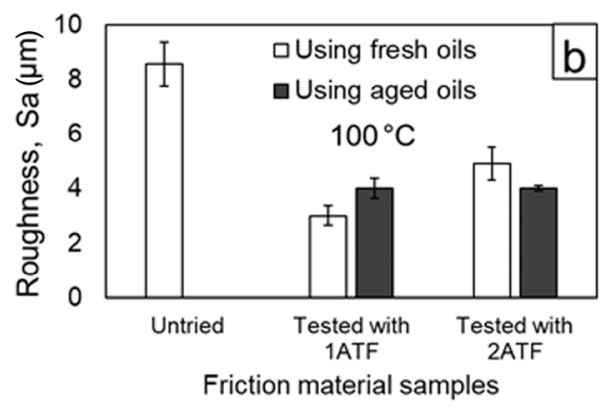

Fig. 12 Comparison of surface roughness ( $\mathrm{Sa}$ ) measured by optical profilometer from the surfaces of the friction material specimens tested at: (a) $26{ }^{\circ} \mathrm{C}$; (b) $100{ }^{\circ} \mathrm{C}$. 


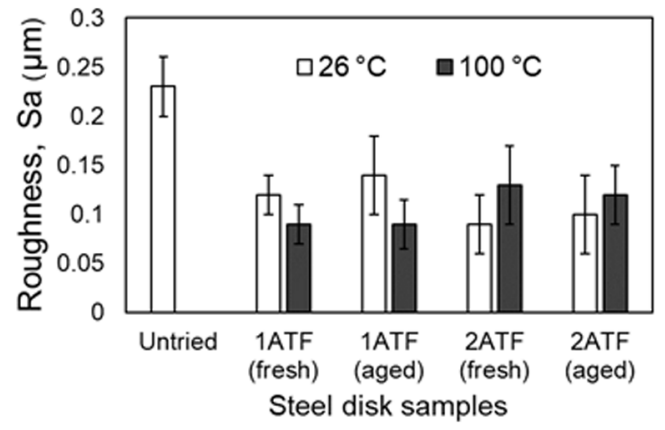

Fig. 13 Comparison of surface roughness (Sa) measured by optical profilometer from the surfaces of the tested steel disks.

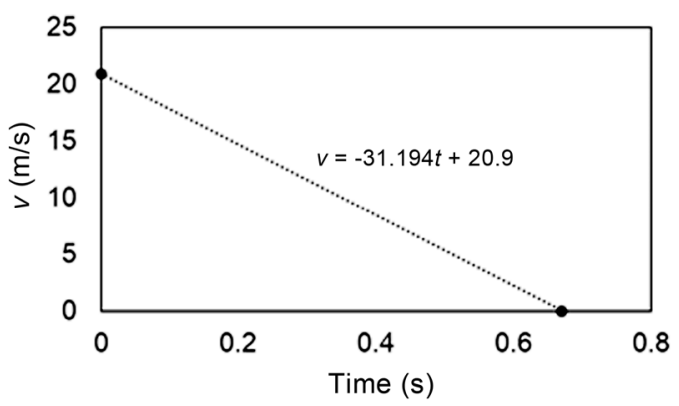

Fig. 14 Linear trend curve from the measured speed vs engagement time curve obtained in a wet clutch test rig.

So, the total sliding distance in a simulated wet clutch engagement was found to be around $7 \mathrm{~m}$. Besides, considering that the average number of wet clutch engagements for gear change from the lowest to the highest in common passenger cars for a finished distance of $100 \mathrm{~km}$ was reported to be around 140 for highway driving [28], it can be proposed that the approached amount of sliding distance in a wet clutch for $100 \mathrm{~km}$ can be around $231 \mathrm{~m}$ under such conditions. Hence, the surface alteration produced in the friction plates for the sliding distances tested $(0,634,1,269 \mathrm{~m})$ could represent the amounts of sliding distance occurred in a wet clutch of a passenger car driven in highway for 0,275 , and $550 \mathrm{~km}$, respectively. These are very short driven distances in comparison with the actual service life of a wet clutch that is expected to be over 200,000 km. Considering this approach and the surface alteration observed in the friction samples, it can be argued that the friction coefficient behavior obtained from these tests corresponds to that behavior exhibited in the running-in stage. The chemical characterization of the tribo-film generated on the surfaces and further glaze formation at much longer sliding distances will be helpful for the understanding of more severe wet clutch service conditions.

\subsubsection{Influence of temperature on wet clutch friction}

The friction coefficients generated by testing both fresh and aged ATFs were lower at $100{ }^{\circ} \mathrm{C}$ than $26^{\circ} \mathrm{C}$, suggesting that friction coefficients are reduced by raising temperature. This reduction of friction with the rise of temperature has been already reported by other authors [10-12]. So, it is related to the activation of additives (friction modifiers) at high temperatures decreasing friction. This reduction of friction may be negative for the anti-shudder property of an ATF because friction is not decreased only at low sliding speeds but also at higher speeds, which cannot improve the slope value in the $\mu / v$ plots. Comparing the Figs. 9 and 10, the slope value of $\mathrm{d} \mu / \mathrm{d} v$ was decreased at $100{ }^{\circ} \mathrm{C}$ for both fresh and aged ATFs. Hence, the increase of temperature can be considered also as a parameter that affects the anti-shudder property of the oils.

It is noteworthy that the results of measurement and discussion of $\mathrm{d} \mu / \mathrm{d} v$ values obtained in this work correspond to results obtained in a pin-ondisk test set-up as a first evaluation, so this research requires of SAE\#II tests to certainly discuss on the anti-shudder property of the oils, which will be subject of future work.

\section{Conclusions}

1) Series of pin-on-disk tests were carried out to determine the friction coefficients at different sliding speeds of a wet clutch using two different automatic transmission fluids (ATFs) and evaluating the effects of oil oxidation, sliding distance, and temperature in the running-in stage.

2) The ATFs presented changes in kinematic viscosity and viscosity index due to oxidation. However, one of the ATFs tested (2ATF) was considerably more oxidized than the other (1ATF) by the same thermal ageing process, so it presented higher increase in viscosity and decrease in viscosity index.

3) The friction coefficients of the wet clutch were 
increased by the ATFs oxidation meanwhile the $\mathrm{d} \mu / \mathrm{d} v$ values were decreased in most cases. It suggested that ATF oxidation could enhance the torque capacity of the wet clutch but reduce the ATF anti-shudder property.

4) Alteration of the surface of friction plates was observed to increase with sliding distance after each run conducted exhibiting a decrease in surface roughness and increase of dark regions on the sample's surface. The sliding distance progression generated decrease of friction coefficients in most cases. However, fresh ATFs exhibited an increase of $\mathrm{d} \mu / \mathrm{d} v$ value for the three runs at both temperatures in contrast to aged ATFs, meaning that fresh ATFs may promote a positive influence in the anti-shudder property at advanced sliding distances in contrast to oxidized ATFs.

5) The sliding distances tested were not enough to produce significant glazing on the friction material specimens, so the results were found to meet wet clutch running-in conditions.

\section{Acknowledgements}

The authors would like to acknowledge to CNMNIPN for the support in the spectroscopic analyses of our oil samples. We also thank to "Laboratorio de Reología y Física de la Materia Blanda" from ESFM-Instituto Politécnico Nacional for the assistance and equipment support for the viscosity measurements of our oil samples.

Open Access This article is licensed under a Creative Commons Attribution 4.0 International License, which permits use, sharing, adaptation, distribution and reproduction in any medium or format, as long as you give appropriate credit to the original author(s) and the source, provide a link to the Creative Commons licence, and indicate if changes were made.

The images or other third party material in this article are included in the article's Creative Commons licence, unless indicated otherwise in a credit line to the material. If material is not included in the article's Creative Commons licence and your intended use is not permitted by statutory regulation or exceeds the permitted use, you will need to obtain permission directly from the copyright holder.

To view a copy of this licence, visit http://creativecommons.org/licenses/by/4.0/.

\section{References}

[1] Berger E J, Sadeghi F, Krousgrill C M. Torque transmission characteristics of automatic transmission wet clutches: Experimental results and numerical comparison. Tribol Trans 40(4): 539-548 (1997)

[2] Ashikawa R, Naruse T, Kurashina H, Matsuoka T, Adachi T, Nakayama T. ATF characteristics required for the latest automatic transmissions. In Proceedings of International Fuels \& Lubricants Meeting \& Exposition, 1993.

[3] Newcomb T, Sparrow M, Ciupak B. Glaze analysis of friction plates. In Proceedings of Powertrain \& Fluid Systems Conference and Exhibition, 2006.

[4] Kugimiya T, Yoshimura N, Mitsui J. Tribology of automatic transmission fluid. Tribol Lett 5: 49-56 (1998)

[5] Ingram M, Noles J, Watts R, Harris S, Spikes H A. Frictional properties of automatic transmission fluids: Part II-origins of friction-sliding speed behavior. Tribol Trans 54(1): 154-167 (2010)

[6] Devlin M T, Li S T, Tersigni S H, Turner T L, Jao T C, Yatsunami K, Cameron T M. Fundamentals of antishudder durability: Part II - fluid effects. In Proceedings of SAE Powertrain \& Fluid Systems Conference \& Exhibition, 2003.

[7] Noles J, Watts R F, Ishikawa M, Saito H. Test methods for determining anti-shudder durability of automatic transmission fluids. In Proceedings of JSAE/SAE International Fuels \& Lubricants Meeting, 2007.

[8] Watts R F, Nibert R K, Tandon M. Anti-shudder durability of automatic transmission fluids: Mechanism of the loss of shudder control. Tribotest 4(1): 29-50 (1997)

[9] Li S T, Devlin M, Tersigni S, Jao T C, Yatsunami K, Cameron T M. Fundamentals of anti-shudder durability: Part I - clutch plate study. In Proceedings of 2003 JSAE/SAE International Spring Fuels and Lubricants Meeting, 2003.

[10] Berglund K, Marklund P, Larsson R. Lubricant ageing effects on the friction characteristics of wet clutches. Proc Inst Mech Eng J J Eng Tribol 224(7): 639-647 (2010)

[11] Marklund P, Larsson R. Wet clutch friction characteristics obtained from simplified pin on disc test. Tribol Int 41(9-10): 824-830 (2008)

[12] Farfan-Cabrera L I, Gallardo-Hernández E A, Vite- 
Torres M, Laguna-Camacho J R. Frictional behavior of a wet clutch using blends of automatic transmission fluid (ATF) and biolubricant (Jatropha oil) in a pin-on-disk tester. Tribol Trans 58(5): 941-946 (2015)

[13] Ost W, De Baets P, Degrieck J. The tribological behaviour of paper friction plates for wet clutch application investigated on SAE\#II and pin-on-disk test rigs. Wear 249(5-6): 361-371 (2001)

[14] Besser C, Schneidhofer C, Dörr N, Novotny-Farkas F, Allmaier G. Investigation of long-term engine oil performance using lab-based artificial ageing illustrated by the impact of ethanol as fuel component. Tribol Int 46(1): 174-182 (2012)

[15] CEC L-48-A-00: Oxidation stability of lubricating oils used in automotive transmissions by artificial ageing. 2007.

[16] Korcek S, Jensen R K. Relation between base oil composition and oxidation stability at increased temperatures. ASLE Trans 19(2): 83-94 (1976)

[17] Marklund P, Mäki R, Larsson R, Höglund E, Khonsari M M, Jang J. Thermal influence on torque transfer of wet clutches in limited slip differential applications. Tribol Int 40(5): 876-884 (2007)

[18] Holgerson M. Optimizing the smoothness and temperatures of a wet clutch engagement through control of the normal force and drive torque. J Tribol 122(1): 119-123 (2000)

[19] Perry A W. Automatic and powershift transmission fluid specifications, differentiating OEM requirement. Transmission Fluids, Expertise and Marketing Performance 4.8. (1999)

[20] Holgerson M. Apparatus for measurement of engagement characteristics of a wet clutch. Wear 213(1-2): 140-147 (1997)

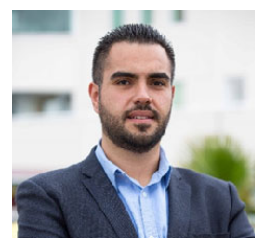

Leonardo Israel FARFAN CABRERA. He received his M.S. and Ph.D. degrees in mechanical engineering from Instituto Politécnico Nacional, Mexico, in 2014 and 2018, respectively. He joined the School of Engineering and Sciences
[21] Uy D, Zdrodowski R J, O’neill A E, Simko S J, Gangopadhyay A K, Morcos M, Lauterwasser F, Parsons G. Comparison of the effects of biodiesel and mineral diesel fuel dilution on aged engine oil properties. Tribol Trans 54(5): 749-763 (2011)

[22] Fatima N, Holmgren A, Marklund P, Minami I, Larsson R. Degradation mechanism of automatic transmission fluid by water as a contaminant. Proc Inst Mech Eng $J J$ Eng Tribol 229(1): 74-85 (2014)

[23] Fatima N, Marklund P, Mathew A P, Larsson R. Wet clutch friction interfaces under water-contaminated lubricant conditions. Tribol Trans 59(3): 441-450 (2016)

[24] Cen H, Morina A, Neville A, Pasaribu R, Nedelcu I. Effect of water on ZDDP anti-wear performance and related tribochemistry in lubricated steel/steel pure sliding contacts. Tribol Int 56: 47-57 (2012)

[25] Tripathi A K, Vinu R. Characterization of thermal stability of synthetic and semi-synthetic engine oils. Lubricants 3(1): 54-79 (2015)

[26] Zhao H Y, Morina A, Neville A, Vickerman R. Anti-shudder properties of ATFs-investigation into tribofilm composition on clutch friction material and steel surfaces and the link to frictional performance. Tribol Trans 55(6): 782-797 (2012)

[27] Zhao H Y, Neville A, Morina A, Vickerman R, Durham J. Improved anti-shudder performance of ATFs-Influence of a new friction modifier and surface chemistry. Tribol Int 46(1): 62-72 (2012)

[28] Danev D. Research of the working loads on the friction clutch of the passenger cars. Ph.D thesis. Belgrade (Yugoslavia): 1978.

and the Nanotechnology research group at Tecnologico de Monterrey since 2018. His current position is assistant professor. His research areas cover the tribology of automotive components and engineering polymers, bio-lubricants, and tribo-testing. 